\title{
PERFORMANCE ANALYSIS OF AN AUTOMATED PRODUCTION SYSTEM WITH QUEUE LENGTH DEPENDENT SERVICE RATES
}

\author{
Al-Hawari, T. ; Aqlan, F. ${ }^{* *}$ \& Al-Araidah, O.* \\ * Industrial Engineering Department, Jordan University of Science and Technology, Irbid, Jordan \\ ** Department of Systems Science and Industrial Engineering, Binghamton University, NY, USA \\ E-Mail: tarek321@hotmail.com, faqlan1@binghamton.edu, alarao@just.edu.jo
}

\begin{abstract}
In this paper, a simulation model is built to analyze the performance of a pull type (Kanban) automated production system with a continuous supply of raw materials and generally distributed demand and service times. The system under consideration represents an attempt of modeling a Kanban controlled production system where the station production rates are dependent on product queue lengths. It is composed of three stations; one of them is a bottleneck station. Stations have different processing speeds (low, medium and high) and are connected by a conveyor system whose actuation is coordinated with the stations. Conveyors transfer the products between stations and provide local buffering of material at the processing tool level. A number of sensors exist on each conveyor to control the processing speed and the operational/stoppage state of the stations. Numerical experiments are conducted to check the model validity and to study the effect of different parameters on the system performance. Results obtained from the simulation model are compared with results obtained from an analytical model built for the same system. The model is used to obtain accurate estimates of the system performance measures such as throughput, waiting queue lengths and work-in-process inventory. Results show that changing sensors' positions affect the system performance considerably. Hence, an optimization study is conducted in order to find the values of sensors' positions that optimize the system performance.

(Received in June 2010, accepted in September 2010. This paper was with the authors 1 month for 2 revisions.)
\end{abstract}

Key Words: Performance Analysis, Automated Production Systems, Kanban, Simulation, Optimization

\section{INTRODUCTION}

Automated production systems consist of automatic workstations connected by a material handling system whose actuation is coordinated with the stations. Ideally, no human workers are needed except to perform auxiliary functions such as tool changing, loading and unloading, and repair and maintenance activities. Modern automatic systems are integrated systems, operating under computer control. The configuration discussed in this paper is widely used in the bottle filling industry for various products such as liquid drugs, mineral water, soft drinks, and food beverages. This configuration optimizes the system performance, prevents congestion and increases system utilization as will be shown later.

The system discussed here represents a fully automated production system consisting of three workstations connected by conveyors that transfer the products between the stations and provide local buffering of material at the processing tool level. The system works under Kanban discipline. Kanban cards or signals provide an efficient mechanism for determining the way production is triggered and inventory is controlled. It regulates the flow of jobs at various stations of the system using a combination of card or signal loops. 
Performance analysis of production systems is intended to design new systems or improve on existing ones. The most common method used for this purpose is modelling, either analytical or simulation. Simulation models represent the events that could occur as a system operates by a sequence of steps in a computer program. Analytical models describe the system using mathematical or symbolic relationships. Analytical models of production systems become more difficult when complexity and/or operational variability increase. In this case, simulation is the most appropriate method to use since it is the only technique able to supply a detailed and dynamic view of the systems, unlike any other analysis tools [1, 2].

In this study, a simulation based model is developed using Rockwell Arena Software [3] to investigate the performance of a Kanban-based automated production system with the purpose of analysing the effect of demand variability, service time variability and the number of Kanbans on the performance measures such as throughput, waiting queue lengths, work-inprocess inventory, utilization etc. Furthermore, an optimization study on the relevant parameters is conducted in order to find the values that optimize the system performance. Numerical experiments are conducted to check the model validity and to study the effect of different parameters on the system performance. The results obtained from the simulation model are compared with results obtained from an analytical model built for the system [4].

\section{LITERATURE REVIEW}

Kanban control policy was invented in Toyota in the 1970s and has since been widely used in industry [5]. The practical success of Kanban systems has then motivated several studies on the design and analysis of these systems such as [6] and [7]. A survey on different simulation, deterministic and stochastic models for the analysis of pull production systems is presented in [8]. The use of simulation for the design and analysis of production systems is widely spread and recognized by scientists and industrial managers and the literature is abundant in this field. Kochhar [9] states that the simulation technique has been used since the 1960s as a tool to investigate the behaviour underlying many types of manufacturing systems. Early simulation work in the area of manufacturing systems began with the study of queuing problems, typically found in the area of production planning. However, during the last three decades, there has been a dramatic increase in the use of simulation to design and optimize manufacturing and warehousing systems. Simulation models are used to model the stochastic nature of pull (Kanban) systems and provide valuable design insights in particular setting such as those conducted in [10] and [11]. There are two approaches to use simulation for studying the Kanban system. One utilizes simulation in order to solve or support mathematical models for the system [12-14]. The other develops simulation models for the Kanban system to analyse the behaviour of the system by varying selected parameters. Davis [15] used simulation to study the effect of the number of Kanbans on the time an order spends on the shop floor. Ebrahimpour and Fathi [16] used dynamic simulation to study a Kanban production inventory system. Aytug et al. [17] used simulation to find the number of Kanbans for a production system working under the pull strategy. Lutz [18] used simulation to determine the buffer location and size in production systems. Hurrion [19] presented an example of simulation optimization using a neural network metamodel to find the optimal number of Kanbans in a manufacturing system. Selvaraj [20] used simulation to find the optimal number of Kanbans in a Generalized Kanban Control System (GKCS) at three different demand frequencies while keeping the mean processing time constant. Marek et al. [21] used Arena/SIMAN to code a flow-type four-stage Kanban system, and to develop a CONstant Work-In-Process or CONWIP model, showing detailed SIMAN codes.

The system discussed in this study differs from the systems discussed in previous studies in that the station production rates are dependent on product queue lengths and the inter- 
arrival and service times are generally distributed. The simulation model built reduces time and effort for modelling drastically, and increases the efficiency of constructing models by only changing a series of parameters. This module-based modelling represents the functionality of the system accurately and easily gives the outputs required. Furthermore, the model can be easily extended to model other systems.

\section{SYSTEM DESCRIPTION}

The system discussed in this study represents a Kanban-based multi-stage automated production system consisting of three workstations connected by a conveyor system whose actuation is coordinated with the stations. Conveyors transfer the products between stations and provide local buffering of material at the processing tool level. The system produces a single product type without any changeover time. The first station is fed by raw material which is assumed to be always present (raw material always exists in the queue before the first station) and the flow of raw material is continuous (the first machine is never starved). The first station has two states, constant speed operation and stoppage. The second and third stations each have four states: low speed operation, medium speed operation, high speed operation in addition to the stoppage state. The system also has three conveyers, the first connects the first station (Forming station) with the second station (Filling station), the second conveyor connects the second station (Filling station) with the third station (Packaging station) and the third connects the third station (Packaging station) with the finished products inventory. The first and the second conveyors have three sensors and the third conveyor has only one sensor as shown in Fig. 1. These sensors control the states of the machines based on the queue length of products on the conveyors.

The system works under the pull (Kanban) discipline which controls the flow of parts among the stations. Empty cells on the conveyor serve as Kanban squares [22], the upstream station checks the outgoing conveyor cells, if any are empty, then it produces a number of parts equal to the number of empty cells. Fig. 1 shows the layout of the system which is typically used in the bottle filling industry. When a customer order comes to the finished goods inventory and products are shipped to the customer, the finished goods inventory pulls parts from conveyor 3 to replenish the shipped parts. At this time, the packaging station produces a number of parts to replenish the parts pulled by the finished goods inventory. When conveyor 3 is full of parts, the sensor labelled $K_{3}$ in Fig. 1 sends signals to the packaging station to stop producing parts. Packaging station pulls parts from conveyor 2, and when there are empty spaces on conveyor 2, the sensor labelled $K_{2}$ in Fig. 1 stops sending signals to the filling station. The filling station then produces parts to fill the empty cells. Similarly, filling station pulls parts from conveyor 1 and when there are empty spaces on conveyor 1 , the forming station produces parts to refill the empty spaces on conveyor 1 . When conveyor 1 is full of parts, the sensor labelled $K_{1}$ in Fig. 1 sends signal to the forming station to stop producing parts. Forming station pulls material from the raw material inventory which is always full and the forming station is never starved. Conveyor 1 has three photocells or sensors; one is located near the end of the conveyor. This sensor, labelled $K_{1}$ in Fig. 1 , controls the stoppage/operational state of the forming machine. If the conveyor is full of parts, the sensor sends signals to the forming machine to stop producing parts. If there are empty cells on the conveyor, the sensor stops signalling the forming machine until it produces the required number of parts needed to fill up the conveyor again. The other two sensors, labelled 1 and 2, control the speed (low, medium and high speed) of the downstream machine on the other end of the conveyor (filling machine). The same arrangement applies for sensors on conveyor 2, one, labelled $K_{2}$, controls the stoppage/operational state of the filling machine and the other two sensors, labelled 3 and 4, control the speed of the packaging machine. On 
conveyor 3, there is only one sensor, labelled $K_{3}$, which controls the stoppage/operational state of the packaging machine. As mentioned earlier, Kanbans are represented by the empty spaces on the conveyors with their number being limited by the physical length of the conveyor and the size of the product being manufactured.

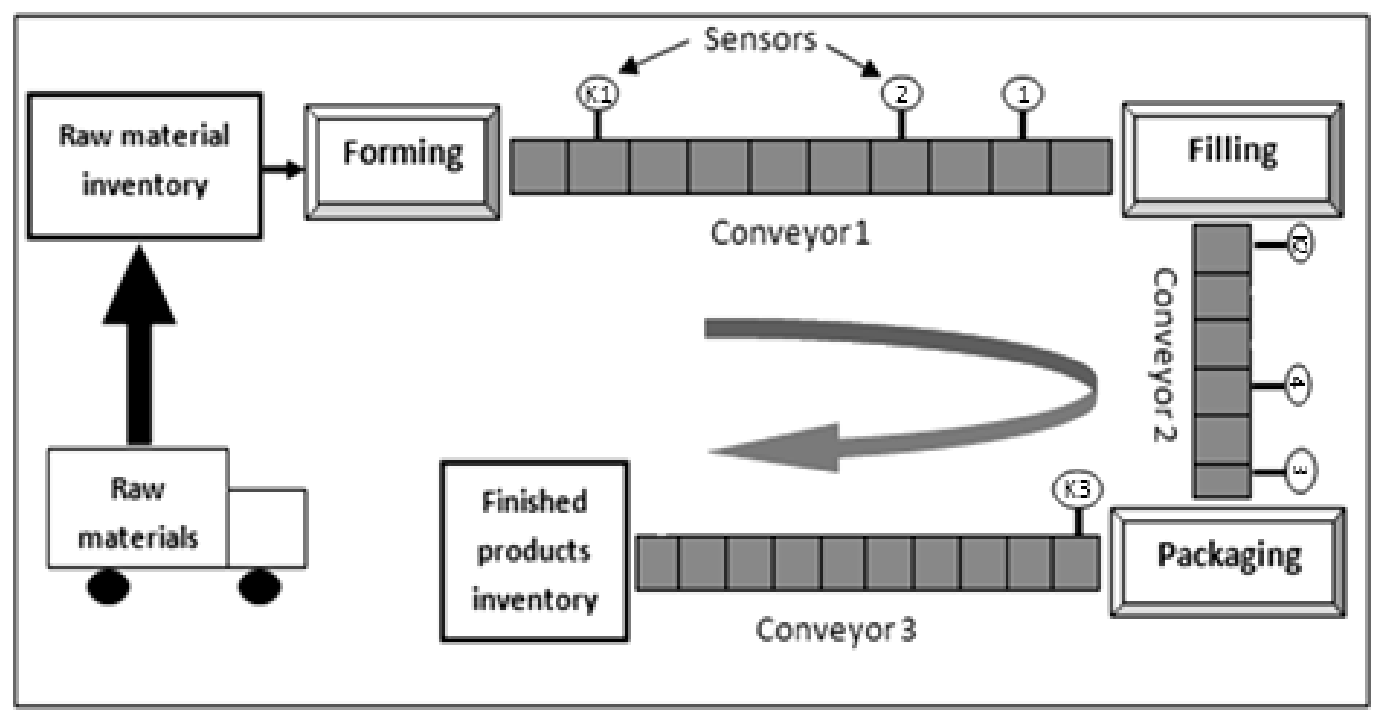

Figure 1: System layout.

When comparing the queue length independent configuration (fixed production rates) with the queue length dependent configuration (variable production rates), it is found that the new configuration optimizes the system performance as shown in Figs. 2 and 3 that show the performance measures (throughput and WIP) of the two configurations. Fig. 2 shows the system throughput results obtained from simulation for the two configurations at different values of the number of Kanbans (10, 20, 30, 45 and 100). Fig. 3 shows the results for the Work-In-Process (WIP). The results are obtained by using three different production rates (high: 1.05, medium: 0.95 and low: 0.85) for the queue length dependent configuration and by using fixed production rate (average: 0.95) for the queue independent configuration.

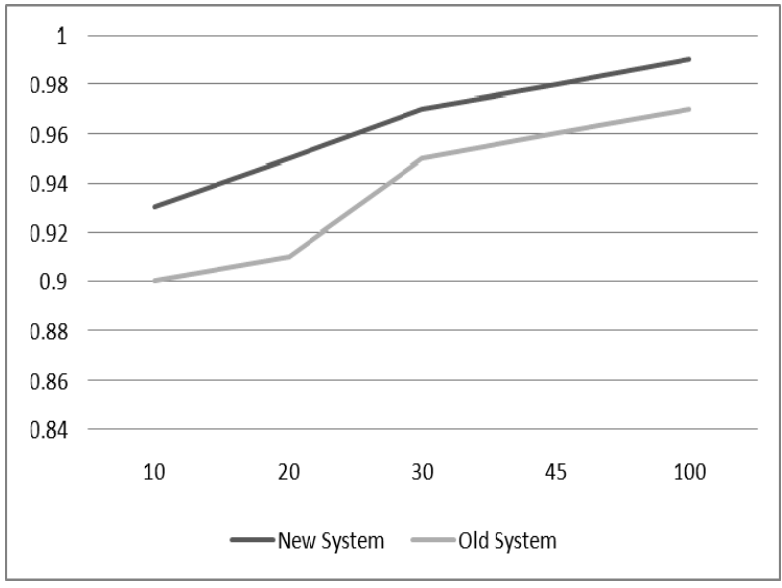

Figure 2: Comparing the system throughput for the queue length dependent and queue length independent configurations at different values of the number of Kanbans.

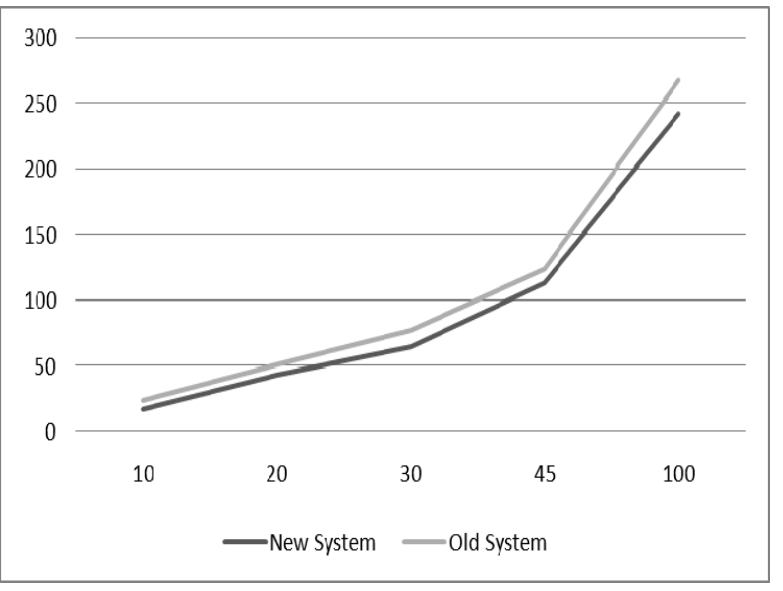

Figure 3: Comparing the system WIP for the queue length dependent and queue length independent configurations at different values of the number of Kanbans. 


\section{SIMULATION}

For the design or improvement of production systems it is important to be able to predict their performance. Performance analysis of Kanban-based automated production systems is not an easy task since these systems operate as integrated systems and a tight control of all parameters of the system is required because each parameter affects the whole system. This task is difficult to implement on the actual system, so models are developed to run experiments and make changes on the system model that may be very costly if performed on the real system. Successful analysis of production systems can be performed through effective modelling that considers the variable machine production rates, buffer capacity, reliability issues, stochastic fluctuations and other factors. It is difficult to build accurate analytical models that include all these factors. However, effective simulation models can be used to analyse such systems successfully. These models are helpful in understanding the detailed behaviour of the system and they are able to integrate internal manufacturing functions with external business processes. Simulation allows managers to obtain a system-wide view of the effect of changes on the system. Before building the simulation model for the system under study, a queuing model is built to help in understanding the system operation. The queuing model is shown in Fig. 4. The system consists of three stages. Each stage consists of a single manufacturing station $(M P)$ with a single machine $(S)$ and has a fixed number of Kanbans $(K)$ that circulate within a loop. The Kanban mechanism controls the movement of parts from stage to stage. This control mechanism is modelled by the synchronization stations at the system and the input/output buffers at each stage $\left(J_{0}, J_{1}, J_{2}\right.$ and $\left.J_{3}\right)$.

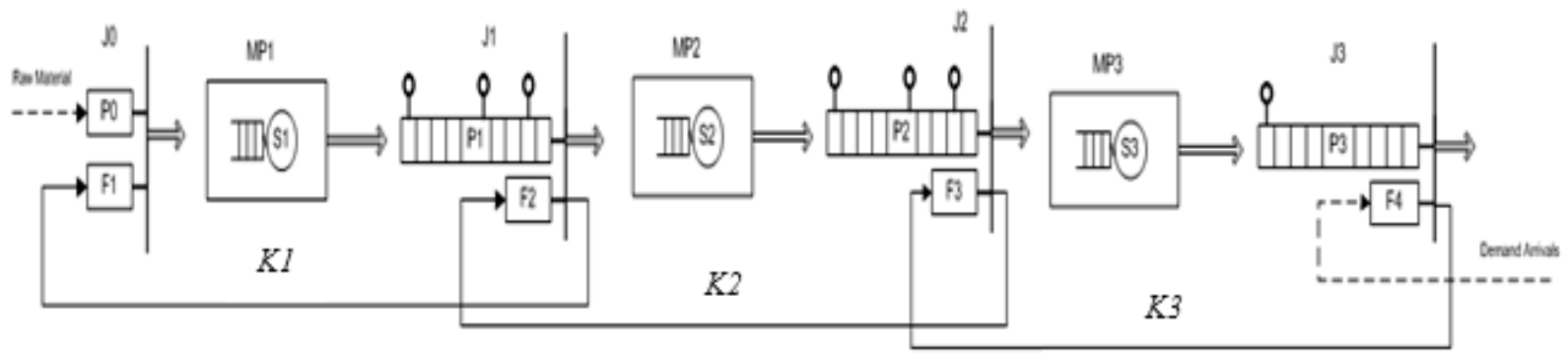

Figure 4: Queuing model representation of the system.

Simulation models are built using a modern simulation software package, Rockwell Arena [3] which gives an analyst a great deal of flexibility. Consequently there are many different possible ways to model Kanban controlled production systems in Arena. One way is to model Kanbans as entities which represents the functionality of the system accurately and easily gives the outputs required. In this case, entities are used to represent the Kanbans and have them flowing through the system alongside the parts. A simple logic for this model is shown in Fig. 5. Parts and Kanbans wait in a queue until a part and a Kanban are available at one station, and then the Kanban is attached to the part and transferred to the manufacturing station as one entity. After processing is completed, the entity wait is a queue for the downstream stage Kanban and when it is available, the upstream stage Kanban is first detached and returned to the first stage while the downstream Kanban is attached with the part and both transferred to the next manufacturing station as one entity. 


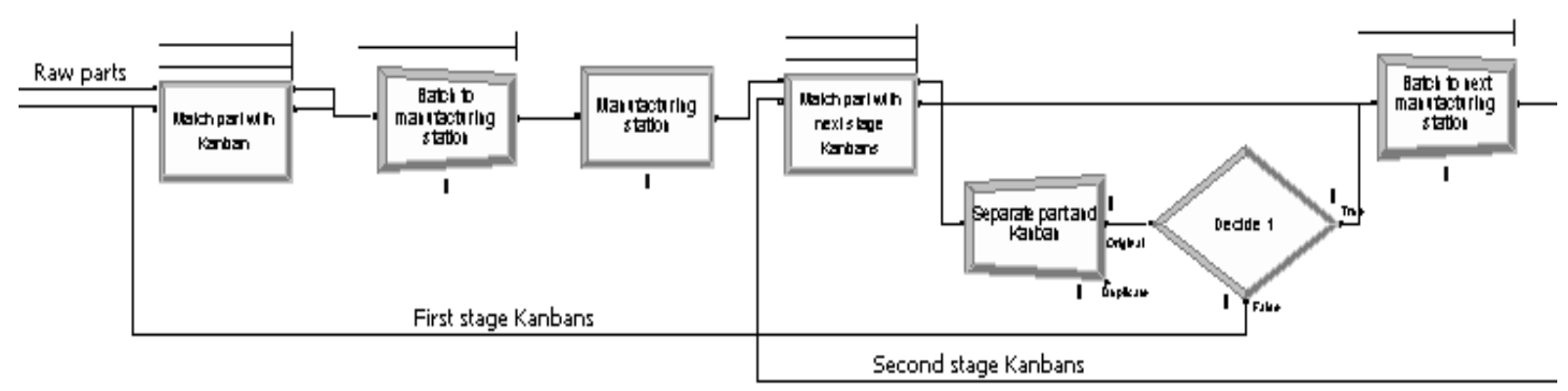

Figure 5: Simple logic of Kanban modelling in Arena.

\section{NUMERICAL EXPERIMENTS}

Four numerical experiments are conducted to check the validity of the model and to study the performance of the system. In the first experiment, the effect of demand variability on system performance is studied. In the second experiment, the effect of service time variability on system performance is studied. The third experiment focuses on the effect of changing the number of Kanbans on system performance and the fourth experiment studies the effect of changing the sensors' positions on system performance. Rockwell Arena Software (version 12) [3] is used and all experiments are run on a Pentium IV PC (CPU: 2.4GHz, RAM: 2 MB). For each experiment, the simulation results are the average of ten to fifty independent runs, each of which represents the production of about 1,000,000 parts or customer orders. For each run, the statistics corresponding to the initial 100,000 parts are discarded (warm up period) to account for transient start-up effects. For each experimental observation, the $95 \%$ confidence intervals are recorded and used to verify the validity of the insights. Since the confidence intervals (half width) were less than 0.001 and don't contribute to any additional insights, they are omitted from the tables presenting simulation results. The computational time required by the simulation to obtain the performance estimates takes about 10 minutes to 30 minutes per run.

\subsection{The first experiment}

In this experiment, the effect of changing customer demand variability on system performance is studied. In each run of the experiment, the demand variability is changed and the system performance measures (throughput and queue characteristics) are recorded. Fig. 4 shows the system throughput for four different demand variabilities $(0.5,0.7,1,2)$ where all stations have the same number of Kanbans i.e. $K_{1}=K_{2}=K_{3}=K_{4}=K$. Demand variability is measured by the squared coefficient of variation or $S C V$, where $S C V=$ (standard deviation of interarrival time $)^{2} /$ (arrival rate) $)^{2} . K_{1}, K_{2}$ and $K_{3}$ represent the number of Kanbans for the first, second and third stage, respectively. $K_{4}$ represents the number customer demand orders or storage places in the finished goods inventory. The experiment is repeated for different values of $K$ of values 10, 20, 30, 45, and 100 which are shown in Fig. 6. The mean production rate and its $S C V$ for the first manufacturing station is assumed to be $(1,1)$ for the first manufacturing station. For the second manufacturing station these parameters are $(0.85,1)$, $(0.95,1)$ and $(1,1)$ (low speed, medium speed and high speed), respectively. For the third manufacturing station the parameters are $(0.9,1),(1,1)$ and $(1.05,1)$. For these states, mean demand arrival rate is assumed to be 1 . Sensors' positions are held at fixed positions on the conveyors, one is positioned at a 1/3 of the conveyer length, the second is at $2 / 3$ s and the third is at the end of the conveyor. Transportation time is negligible as the transportation between production stages is always much shorter than the production time at the production stage. 
Numerical results show that increasing demand variability decreases the system throughput for all cases of $K$ as shown in Fig. 6. It is also shown in Fig. 7 that system throughput is an increasing function of the number of Kanbans for the same demand variability but is limited by the demands and processing rates of the manufacturing stations.

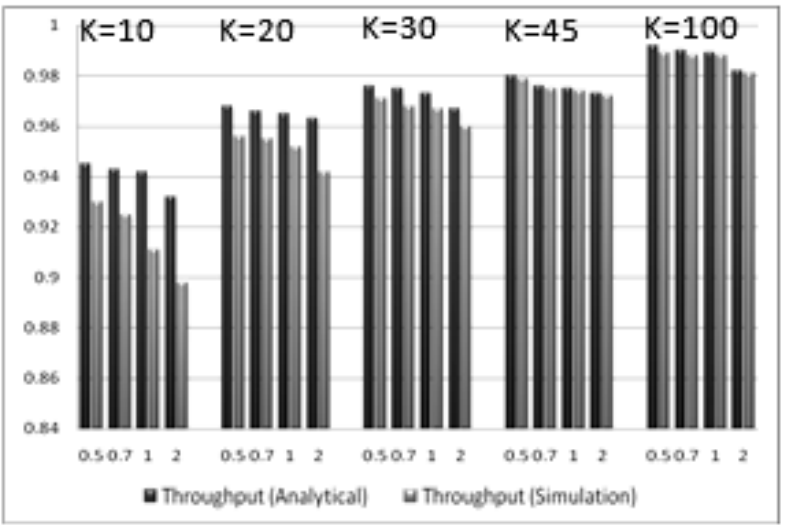

Figure 6: Impact of increasing demand variability on system throughput.

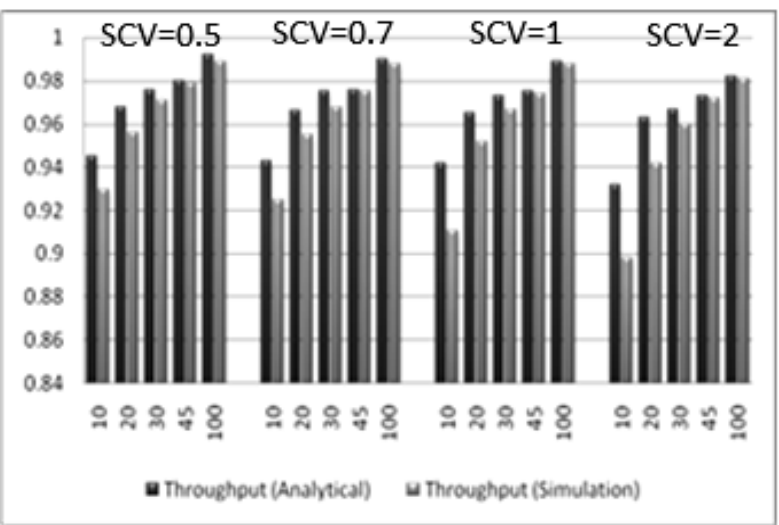

Figure 7: Impact of increasing the number of Kanbans on system throughput.

\subsection{The second experiment}

In the second experiment, the effect of service time variability on the system performance is studied. Service time variability is changed in each run and the other parameters are held constant. The values of the parameters used in this experiment are the same as those used in the previous experiment except for the $S C V$ s of the production rates of the manufacturing stations which are varied between 0.7 and 2, where all stations have the same variability. The $S C V$ s are changed in every run of this experiment to study their effect. Results indicate that increasing the service time variability decreases the system throughput as shown in Fig. 8 (for $K$ 's $=30$ ) and Fig. 9 (for $K$ 's = 50).

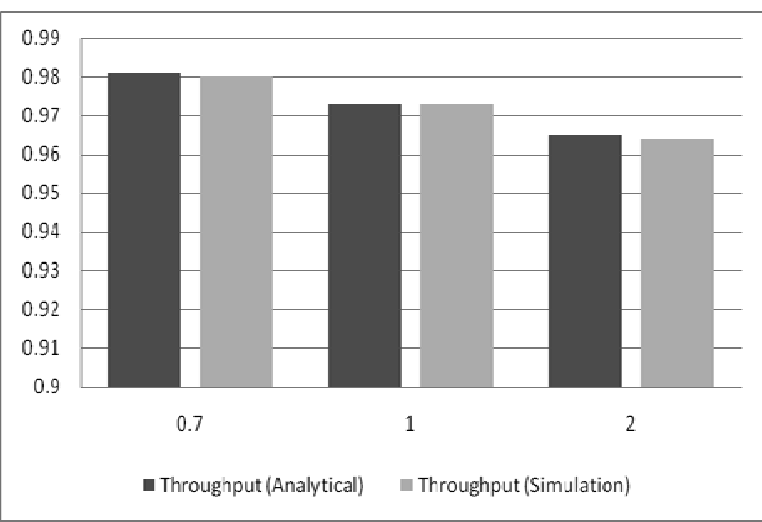

Figure 8: Impact of increasing service time variability on system throughput $(K$ 's $=30)$.

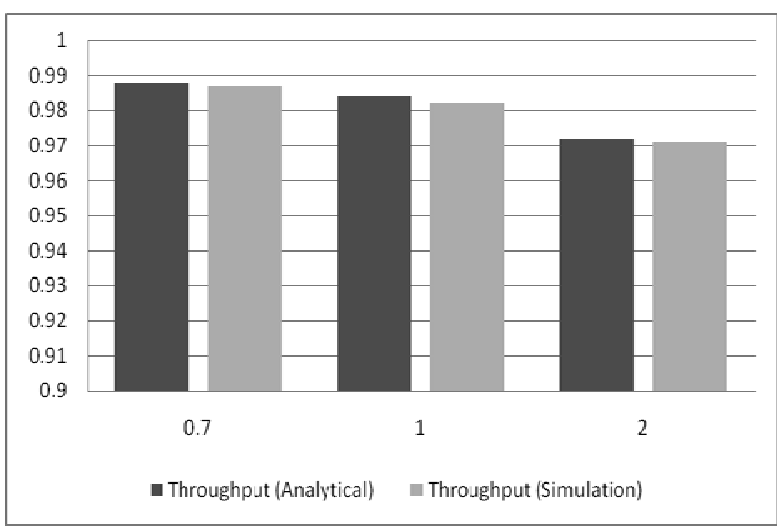

Figure 9: Impact of increasing service time variability on system throughput $(K$ 's $=50)$.

\subsection{The third experiment}

In this experiment, the effect of having different number of Kanbans in each stage on the system performance is studied. All parameters are held constant except for the number of Kanbans. In each run of the experiment, the number of Kanbans of one stage is changed (30, 50, 100 and 300) while the other stages' Kanbans are held constant at $K=30$. Figs. 10 and 11 
show the result for $K_{4}, K_{3}, K_{2}$ and $K_{1}$, repectively. Fig. 10 indicates that increasing the number of Kanbans for each stage independently will increase the system throughput slightly and this effect is amplified at the the second stage since it is the bottleneck. For the total WIP in the system, increasing the value of $K_{4}$ has a minimal effect while increasing the value of $K_{3}, K_{2}$ and $K_{1}$ increases the total WIP as shown in Fig. 11.

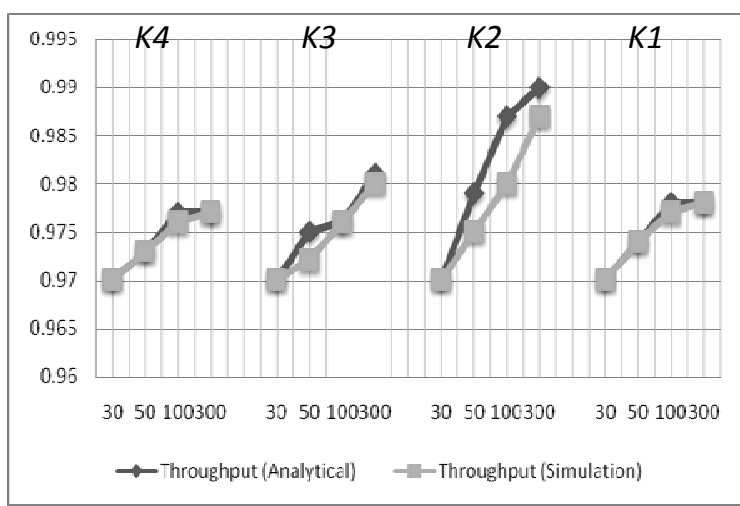

Figure 10: Impact of increasing the number of Kanbans on system throughput.

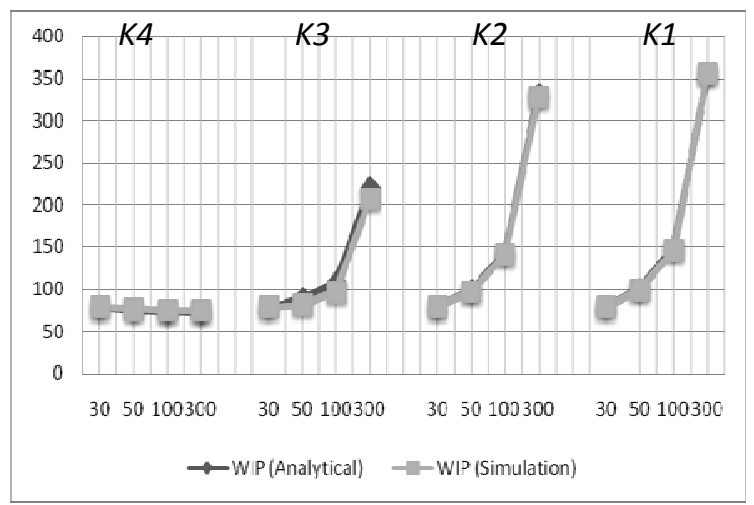

Figure 11: Impact of increasing the number of Kanbans on total WIP.

\subsection{The fourth experiment}

Here the effect of changing the sensors' positions on the system performance is studied and the positions that optimize the system performance are determined. Results are recorded for six sets of sensors' positions on conveyors 1 and 2 as shown in Table I where each position is given as the number of cells from the downstream end of the conveyor to the sensor's position. It is assumed that the number of Kanbans for all stages are equal, i.e. $K_{1}=K_{2}=K_{3}=$ $K_{4}=K$. The experiment is repeated for two different values of $K, 50$ and 100 . The results for system throughput and WIP are shown in Figs. 12 and 13 respectively. Results indicate that changing sensors' positions affects the system performance consideraby. The next section discusses the optimization process using OptQuest for Arena to find the optimal positions for the sensors.

Table I: Input parameters and results for the fourth experiment.

\begin{tabular}{|c|c|c|c|c|c|c|c|c|c|c|c|}
\hline \multirow{2}{*}{ Case } & \multicolumn{4}{|c|}{ Input parameters } & \multicolumn{3}{c|}{ Throughput } & \multicolumn{3}{c|}{ Total WIP } \\
\cline { 2 - 12 } & K's & Sensor1 & Sensor2 & Sensor3 & Sensor4 & $A$ & $S$ & $E \%$ & $A$ & $S$ & $E \%$ \\
\hline 1 & 50 & 17 & 33 & 17 & 33 & 0.984 & 0.982 & 0.204 & 115.230 & 126.700 & -7.647 \\
\hline 2 & 50 & 17 & 33 & 25 & 40 & 0.970 & 0.981 & -1.121 & 139.934 & 134.360 & 3.716 \\
\hline 3 & 50 & 15 & 40 & 10 & 30 & 0.986 & 0.985 & 0.101 & 124.499 & 124.200 & 0.597 \\
\hline 4 & 100 & 20 & 80 & 30 & 70 & 0.994 & 0.990 & 0.404 & 230.747 & 255.220 & -8.158 \\
\hline 5 & 100 & 33 & 66 & 33 & 66 & 0.993 & 0.991 & 0.202 & 232.124 & 256.640 & -8.170 \\
\hline 6 & 100 & 40 & 80 & 40 & 80 & 0.985 & 0.990 & -0.505 & 250.324 & 265.080 & -4.919 \\
\hline
\end{tabular}




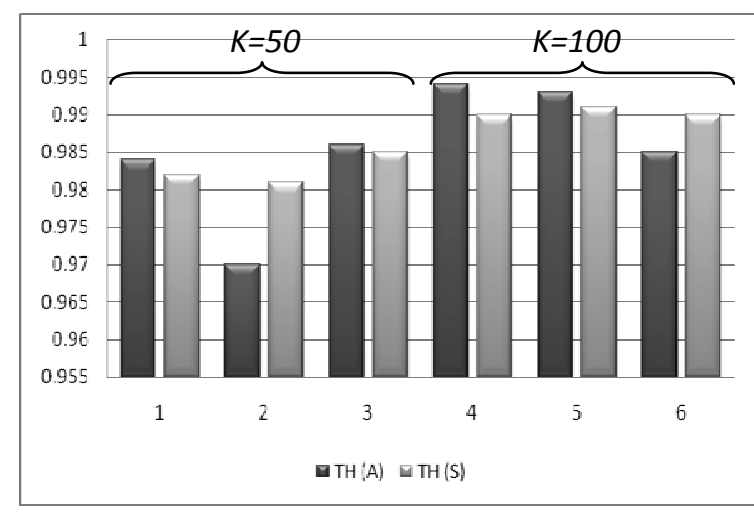

Figure 12: Impact of changing sensors’ positions on system throughput.

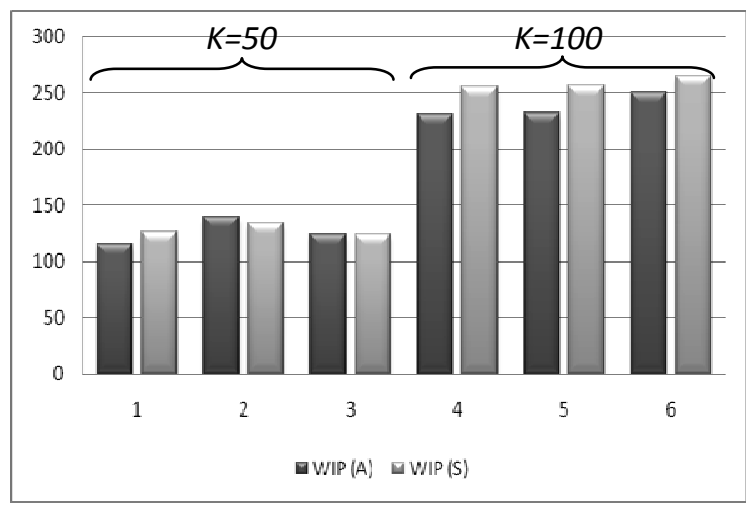

Figure 13: Impact of changing sensors' positions on total WIP.

\section{OPTIMIZATION OF SENSORS’ POSITIONS}

OptQuest for Arena [1, 3] is an application that changes selected model inputs and then searches for a combination of these inputs that would optimize (maximize or minimize) a certain output performance measure [1]. In the optimization process for the current system, the input parameters are the sensors' positions and the output performance measure to be maximized is the system throughput. Sensors' positions are first defined as variables in the main model. The objective function and constraints are defined as follows:

max system throughput-WIP

subject to

sensor3 position $\leq$ sensor4 position

sensor 1 position $\leq$ sensor 2 position

$K_{1}>$ sensor1 position $>0$

$K_{1}>$ sensor 2 position $>0$

$K_{2}>$ sensor3 position $>0$

$K_{2}>$ sensor4 position $>0$

All sensor position values are discrete (integers) and step size $=1$.

where, $K_{1}$ and $K_{2}$ are the number of Kanbans of the first stage and the second stage. Their values represent the number of conveyor cells for conveyor 1 and conveyor 2, respectively. The optimal positions are determined for equivalent values of $K$ for all stages. The optimization time is about 118 hours ( 5 days) for $K=50$ and about 341 hours (14.21 days) for $K=100$. For $K=50$, sensors 2 and 3 are eliminated which indicates that the filling machine will now have only three states, low speed operation, high speed operation and stoppage. For $K$ 's $=100$, sensor is eliminated which indicates that the packaging machine will now have three states instead of four, namely medium speed operation, high speed operation and stoppage. The results show that the system throughput is maximized and Work-In-Process (WIP) is minimized as shown in Table II.

Table II: OptQuest optimization results.

\begin{tabular}{|c|c|c|c|c|c|c|c|c|c|c|}
\hline \multirow{2}{*}{ K's } & \multicolumn{4}{|c|}{ Optimal Sensors' positions } & \multicolumn{3}{c|}{ Throughput } & \multicolumn{3}{c|}{ WIP } \\
\cline { 2 - 11 } & Sensor1 & Sensor2 & Sensor 3 & Sensor4 & $A$ & $S$ & $E \%$ & $A$ & $S$ & $E \%$ \\
\hline 50 & 6 & 6 (eliminated) & 1 (eliminated) & 11 & 0.991 & 0.990 & 0.101 & 118.005 & 119.440 & -0.957 \\
\hline 100 & 1 (eliminated) & 28 & 31 & 37 & 0.996 & 0.997 & -0.100 & 225.134 & 245.210 & -6.692 \\
\hline
\end{tabular}




\section{CONCLUSIONS}

The study shows how simulation can be used to analyse the performance of a pull type (Kanban) automated production system where the station production rates are dependent on product queue lengths. The model built provides an in-depth understanding of the system and its functionality. Furthermore, it provides the opportunity to run numerical experiments on the system to study the effect of different parameters on system performance measures. This is extremely difficult to perform on a real system. Conducted numerical experiments show that:

a) variability in demand and variability in processing time have a direct impact on system performance; this could help the manager in prioritizing the investment in variability reduction in the system,

b) in general, the numerical results indicate that throughput of the Kanban system is an increasing function of the number of Kanbans but is limited by the arrival rates of demands and the processing rates of the manufacturing stations; the second stage has the largest effect since it is the bottleneck,

c) for total WIP, increasing the value of customer orders Kanbans has no effect while increasing the value of $K_{3}, K_{2}$ and $K_{1}$ increases the total WIP,

d) changing sensors' positions affect the system performance and the the optimal positions are found using OptQuest for Arena.

The model can also be used to determine the optimal number of Kanbans required for each stage. Furthermore, it can be extended or modified easily to be used for production systems working under material control strategies other than Kanban such as CONWIP and POLCA or systems producing different types of products.

\section{REFERENCES}

[1] Kelton, D.; Sadowski, R.; Sturrock, D. (2007). Simulation with Arena, McGraw-Hill, New York

[2] Wang, Q.; Chatwin, C. (2005). Key issues and developments in modeling and simulation-based methodologies for manufacturing systems analysis, design and performance evaluation, International Journal of Advanced Manufacturing Technology, Vol. 25, 1254-1265

[3] Rockwell Automation. Arena, from http://www.arenasimulation.com, accessed on 01-03-2010

[4] Aqlan, F. (2010). Performance analysis and evaluation of an automated production system working under the Kanban discipline, MSc Thesis, Jordan University of Science and Technology, Irbid, Jordan

[5] Monden, Y. (2007). Toyota Production System: Practical Approach to Production Management, Industrial Engineering and Management Press, Narcross, GA

[6] Buzacott, J.; Shanthikumar, J. (1993). Stochastic Models of Manufacturing Systems, Prentice Hall, New Jersey

[7] Hopp, W.; Spearman, M. (2001). Factory physics, McGraw Hill, New York

[8] Uzsoy, R.; Martin-Vega, L. (1990). Modeling Kanban-based demand-pull systems: a survey and critique, Manufacturing Review, Vol. 3, No. 3, 155-160

[9] Kochhar, A. (1989). Computer Simulation of Manufacturing Systems - Three Decades of Progress, Proceedings of the third European Simulation Congress, Murray-Smith, D.; Stephenson, J.; Zobel, R. N. (Eds.), Society for Computer Simulation, San Diego, 3-9

[10] Gstettner, S.; Kuhn, H. (1996). Analysis of production control systems kanban and CONWIP, International Journal of Production Research, Vol. 34, No. 11, 3253-3273

[11] Zhou, X.; Luh, P. (2000). The performance of a new material control and replenishment system: a simulation and comparative study, Proceedings of the Quick Response Manufacturing 2000 Conference, Suri, R. (Ed.), Society of Manufacturing Engineers, Dearborn, MI, 807-826

[12] Kimura, O.; Terada, H. (1981). Design and analysis of pull system, a method of multi-stage production control, International Journal of Production Research, Vol. 19, No. 3, 241-253 
[13] Mitra, D.; Mitrani, I. (1990). Analysis of a kanban discipline for cell coordination in production lines, Management Science, Vol. 36, 1548-1566

[14] Krishnamurthy, A.; Suri, R. (2006). Performance analysis of single stage Kanban controlled production systems using parametric decomposition, Queuing Systems: Theory and Applications, Vol. 54, 141-162

[15] Davis, W.; Stubitz, S. (1987). Configuring a Kanban system using a discrete optimization of multiple stochastic processes, International Journal of Production Research, Vol. 25, No. 5, 721740

[16] Ebrahimpour, M.; Fathi, B. (1985). Dynamic simulation of a Kanban production inventory system, International Journal of Operations and Production Management, Vol. 5, No. 1, 1-14

[17] Aytug, H.; Dogan, C.; Bezmez, G. (1996). Determining the number of kanbans: a simulation metamodeling approach, Simulation, Vol. 67, No. 1, 23-32

[18] Lutz, C. (1995). Determination of buffer location and size in production lines using tabu search, European Journal of Operational Research, Vol. 106, 301-316

[19] Hurrion, R. (1997). An example of simulation optimization using a neural network metamodel: finding the optimum number of kanbans in a manufacturing system, Journal of Operational Research Society, Vol. 48, 1105-1112

[20] Selvaraj, N. (2009). The optimization of number of kanbans in GKCS with simulation technique, ARPN Journal of Engineering and Applied Sciences, Vol. 4, No. 5, 44-52

[21] Marek, R.; Elkins, D.; Smith, D. (2001). Understanding the fundamentals of Kanban and CONWIP pull systems using simulation, Proceedings of the 2001 Winter Simulation Conference, Piscataway, New Jersey, 921-929

[22] Askin, R.; Goldberg, J. (2002). Design and analysis of lean production systems, Wiley, London 